\title{
Parallel-Connected Solar Photovoltaic with Ultra Low Voltage DC/DC Converter
}

\author{
Zhiwen Yu, Da Xie, and Junqi Feng
}

\begin{abstract}
In series-connected wiring scheme, the residual energy generated by partially shaded cells cannot be collected or, worse, impedes collection of power from the remaining fully illuminated cells. In this paper, a parallel-connected topology is introduced to PV panel. Each cell, connected to the dc bus paralleled with a special converter, is treated as a voltage source. The dc-dc converter is introduced to realize the method, which could work under an ultra-low-voltage (ULV). Efficiency comparison is discussed with a valid calculation. Experiments about the converter, PV cell and the parallel-connected panel are given. The results show that the novel system has a good working characteristic and the efficiency is higher than that of the conventional.
\end{abstract}

Index Terms-Solar photovoltaic, parallel-connected, converter, ULV, efficiency.

\section{INTRODUCTION}

Distribution generation (DG) is one of the most important parts in smart grid, and has been gaining increasingly attention in recent times [1]. Wind turbines, gas turbines, fuel cells and solar cells are widely used in our life. Among these renewable energy, Solar energy provides several advantages such as being harmless to the environment and renewable and photovoltaic (PV) is expected to play an important role in the future [2 4]. Therefore, a great deal of research effort is dedicated to enhance their performance and efficiency at the component and system level [5 8]. Nowadays, the worldwide installed PV power shows a nearly exponential increase and the overall efficiency should be even higher trying to avoid a sensible cost increase.

In PV arrays, cells are conventionally connected in series to obtain the desired voltage. In higher voltage applications, bypass diodes may be placed across groups of cells to prevent mismatch of shaded cells. A typical array panel is composed of 30-36 series-connected solar cells, with an open-circuit voltage near 20V and a short-circuit current around $3 \sim 4 \mathrm{~A}$ [9] If bypass diodes are not used, the shaded cells may act as a load, draining power from better illuminated cells. If bypass diodes are used, the fraction of energy generated by the partially shaded is still lost. However, while the system is not appropriately protected, hot-spot problems can arise, and the system could be damaged [10]. Efficiency of commercial PV is very low and system with bypass diodes is more susceptible to lose power due to the shadowing of their PV modules [11].

Manuscript received October 20, 2012; revised November 29, 2012.

The authors are with Shanghai Jiao Tong University, No.800 Dongchuan Rd, Shanghai, China (e-mail: yuzhiwen@sjtu.edu.cn, profxzg@hotmail.com, syfjq@126.com).
Due to the fact that the little capability of PV cells converting light directly to electricity, it has stimulated new research areas on PV cells so that the PV array applications have emerged as an important solution to the growing energy crisis since 1970s [12]. Researchers take the PV array as a whole. However, mismatching losses, partial shadow, variations in current-voltage characteristics of PV cells may cause energy loss, which makes it hard to collect their power. It seems impossible to use the power directly without auxiliary devices because voltage and energy in one cell is ultra-low. So, use the ultra-low voltage is necessary which a sophisticated technique is.

\section{EFFICIENCY COMPARISON}

Suppose the cells number in a PV panel is $n * p, n$ is series number and $p$ is the parallels, in usual $n>p$. Assume that all cells are the same and put in the same illumination. As some of cells are work in shadow, energy of the particular series cannot be collected because the voltage is lower than others. The rest energy can be collected in a low voltage until the number of error cells in every series is the same.

Assume that $i$ is the number of cells in shadow, $A(j)$ is the probabilities while the loss power parallels number is $j$ and $j \leq \min (i, p)$.

In conventional topology, $A(j)$ can be calculated in formula (1):

$$
\begin{gathered}
A(1)=\frac{C_{p}^{1} C_{n}^{i}}{C_{n^{*} p}^{i}}\left(\frac{\operatorname{sign}(1-i / n)+1}{2}\right) \\
A(j)=\left(\frac{C_{p}^{j} C_{n^{*} j}^{i}}{C_{n^{*} p}^{i}}-\frac{C_{p}^{j-1} C_{n^{*}(j-1)}^{i}}{C_{n^{*} p}^{i}}\right)\left(\frac{\operatorname{sign}(j-i / n)+1}{2}\right)
\end{gathered}
$$

where $\operatorname{sign}(x)=\left\{\begin{array}{ll}-1 & x \leq 0 \\ 1 & x>0\end{array}\right.$;

When $\bmod (i, p)=0$, the situation that the number put in low light in each serie is the same, the probability can be estimated in formula (2):

$$
B(t)=\frac{\left(C_{n}^{t}\right)^{p}}{C_{n^{*} p}^{i}}
$$

where $t=i / p$, and $t$ is an integer.

So the efficiency in PV panel is the expected value, as 
formula (3) shows.

$$
\eta(i)= \begin{cases}\frac{\sum_{j=1 .}^{\min (i, p)} A(j) *(p-j)^{*} n}{n^{*} p}+\frac{B(t)^{*} p^{*}(n-t)}{n^{*} p} & \bmod (i, p)=0 \\ \frac{\sum_{j=1 .}^{\min (i, p)} A(j)^{*}(p-j)^{*} n}{n^{*} p} & \bmod (i, p) \neq 0\end{cases}
$$

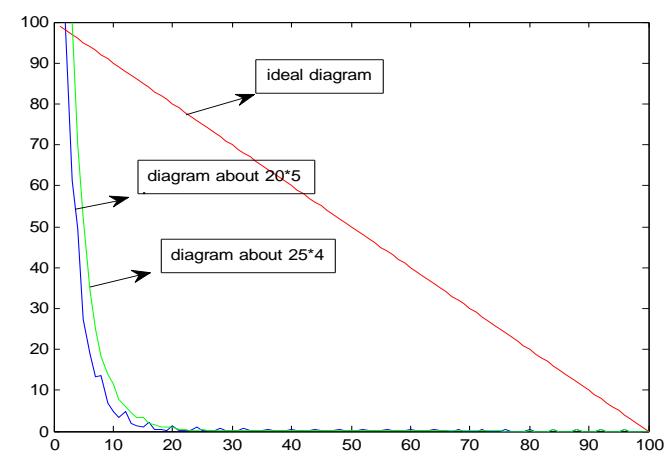

Fig. 1. Efficiency comparison

In the parallel-connected PV system, cells don't affect each other, so the efficiency can be calculated as formula (4) shown:

$$
\eta(i)=\frac{n^{*} p-i}{n^{*} p}
$$

Set $n=20$, the efficiency compasion figure is shown in Fig. 1.

In conventional PV system, efficiency drops rapidly (from $100 \%$ to $10 \%$ ) with the increasing of error cells. When the number of error cells is more than 10 , efficiency is very low, less than $10 \%$. Actually, error cells are usually less than $10 \%$ in small PV panel, efficiency is high. But in the large solar power plant, the number is large, the efficiency will be less than $10 \%$.

In parallel-connected system, the efficiency is high, which acts as an ideal figure in Fig. 1. As the author says in [9], efficiency in series-connected topology is little.

\section{UltRA-LOW-VOLTAGE CONVERTER}

Fig. 2 shows a conventional boost DC-DC converter circuit. When all components are working at their safety state, the output voltage is show in formula (5).

$$
V_{\text {out }}=\frac{1}{1-D} V_{\text {in }}
$$

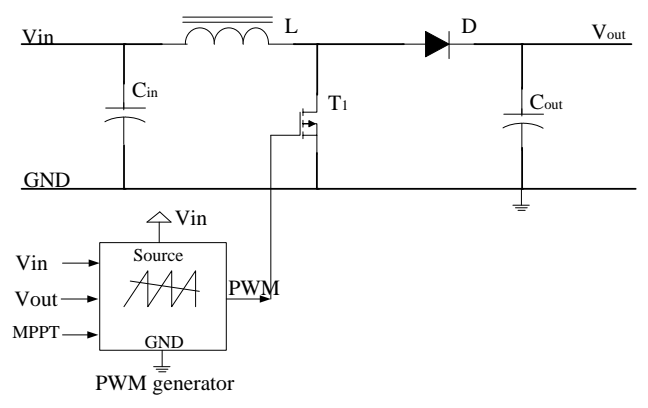

Fig. 2. Conventional boost converter

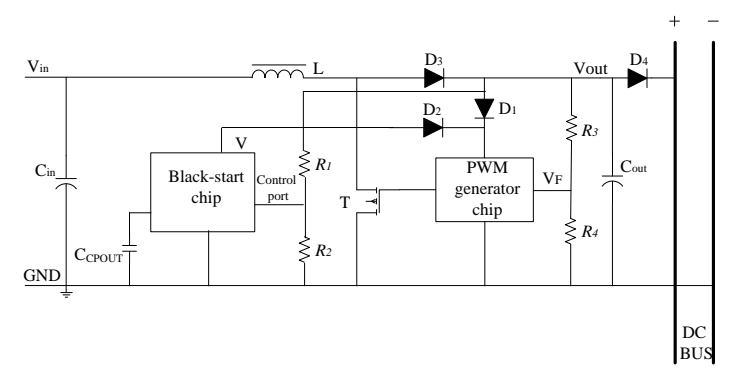

Fig. 3. ULV converter

However, when the input voltage is ultra low, there are two important issues.

- The pulse width modulation generator chip cannot work because The input voltage is low.

- THE duty ratio D is not big enough for the output.

While the input voltage is very low or varies a lot, we can't use it as the control chips' work sourse, but the output voltage is stable when the circuit works as normal, so we can use the output voltage instead. However, when the system is out of work for a long timet, the converter cannot work while the light comes up again. So a black-start chip for the circuit is necessary. Also, maximum value of D should be high enough for the output voltage.

Based on the above analysis, this paper brings out an ULV boost converter to use the special energy, shown in Fig.3. In the converter, all boost circuit is connected to the bus with a schottky diode. Resistance $\mathrm{R}_{3}$ and $\mathrm{R}_{4}$ are used to regulate the voltage. Two diodes, $\mathrm{D}_{1}$ and $\mathrm{D}_{2}$, are used to choose the source power for the control chip. The two diodes compete with each other; when the whole system has stopped, the black-start chip will provide power to the controller while the light comes up in a little. While the circuit is work as usual, the output voltage is higher than that of the black-start chip. When the circuits are working at their state, the black-start chip should be lay-off, so a control circuit, consist of R1 and R2, is very important.

\section{PERFORMANCE OF THE ULV CONVERTER AND EXPERIMENT OF PARALLEL-CONNECTED PV PANEL}

\section{A. Performance of the ULV Converter}

Voltage of a single cell is about $0.5 \sim 0.6 \mathrm{~V}$. In our experiments, the black-start chip is S-822Z_C and the PWM generator chip is $\mathrm{S}-8337$. The output voltage is $6 \mathrm{~V}$. When the input voltage changes from 0 to $2.5 \mathrm{~V}$, the results are shown in Fig. 4.

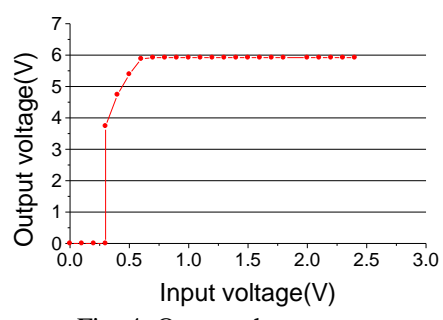

Fig. 4. Output character

In Fig. 4, when the input voltage is lower than 0.4, the output voltage is 0 . Then, the output voltage increases while the input voltage rises up, when the input voltage is larger than 0.6 , the output voltage maintains stability at $5.92 \mathrm{~V}$. 


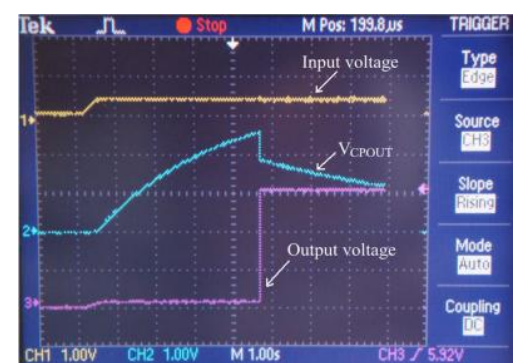

Fig. 5. Input, startup's capacitor and output voltage

Fig. 5 shows the voltage waveforms of input voltage, startup capacitor and output voltage. When the input voltage rises to $0.4 \mathrm{~V}$, the black-start chip starts to work and produces a high voltage. About $4 \mathrm{~s}$ later, $\mathrm{V}_{\mathrm{CPOUT}}$ reaches the discharge voltage. Voltage generated by the black-start circuit drives the PWM generator chip to operate. Then all the circuits are running and the output voltage is increased to $5.92 \mathrm{~V}$.

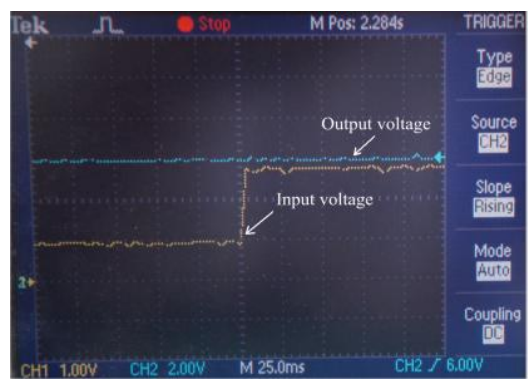

Fig. 6. Output with different input

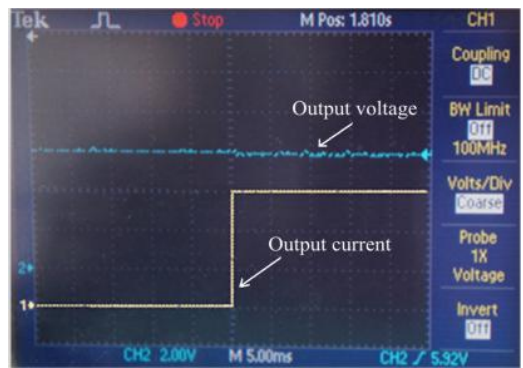

Fig. 7. Output voltage with variation load

Fig. 6 shows the output characteristics in respond to the change of input voltage. When $V_{\text {in }}$ transforms from $1 \mathrm{~V}$ to $2.8 \mathrm{~V}, V_{\text {out }}$ remains itsself. Fig.7 shows the output characteristics with the variation load.

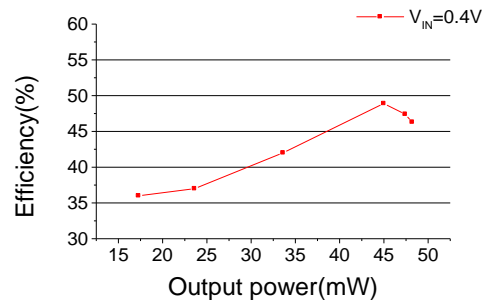

(a)

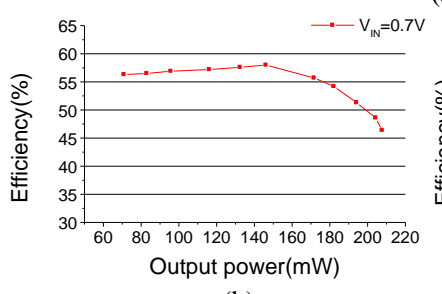

(b)

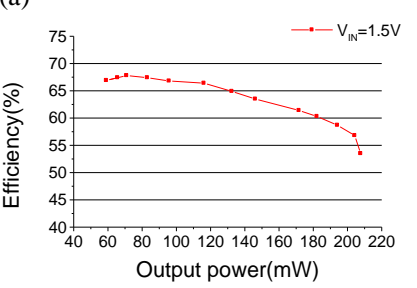

(c)
Fig. 8. Efficiency under input voltage

Fig. 8 shows the efficiency waveform under different input voltage. The efficiency isn't high if the converter operates at the ultra low voltage shown in Fig.8 (a). Fig.9 shows the characteristics of efficiency under different power, 75, 220 and $400 \mathrm{~mW}$. The minimum efficiency of ULV converters rises up with the increase of output power. When the output power is stability. the efficiency is higher with the increase of the input voltage.

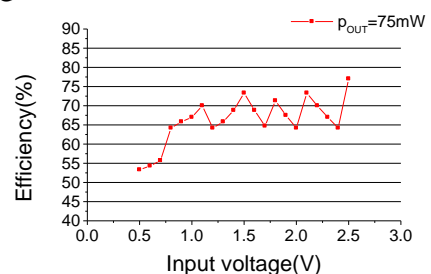

(a)

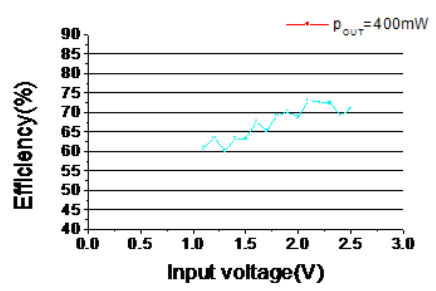

(b)

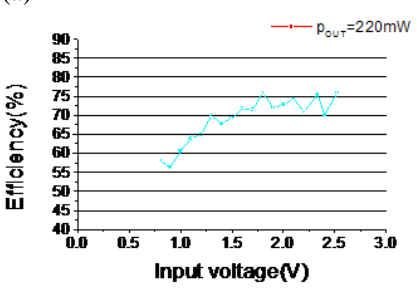

(c)
Fig. 9. Efficiency under different power

\section{B. Experiment of Parallel-Connected PV Panel}

Voltage of a single PV cell is ultra low, and power is little. To test whether the ULV converter can be used for a single cell or not, a circuit is used to estimate a cell's characteristics. The following diagram shows the results of $100 \mathrm{PV}$ cells. The results are the average, shown in Fig.10.

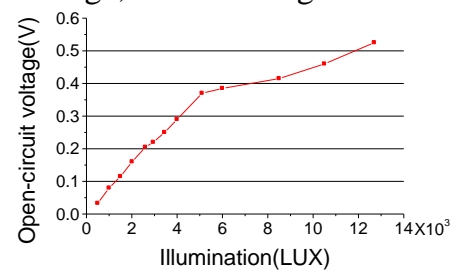

(a) outout voltage

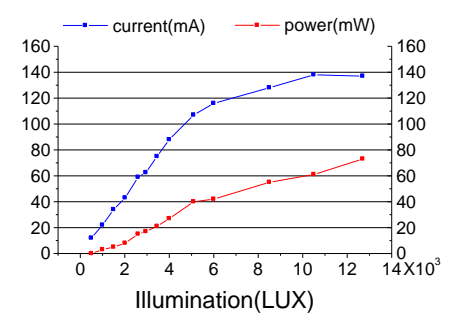

(b) output current and power

Fig. 10. A single PV cell's characteristic

When the illumination is more than 6000 LUX, the output voltage is over 0.4 and its power is $40 \mathrm{~mW}$. That is to say, the converter could convert a cell's power well, and would have a good characteristic.

Combine the PV cell with the ULV converter. Fig.11 and Fig.12 shows the results when the panel is put in different illumination.

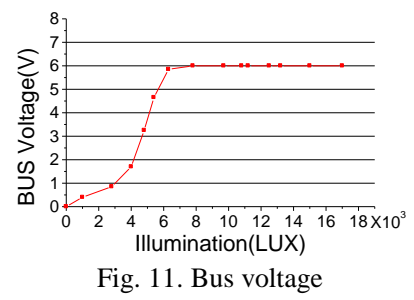




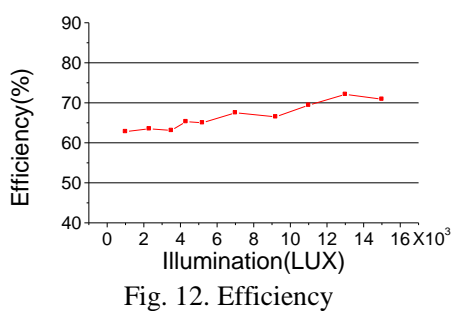

Voltage of the dc bus is stable while the illumination is higher than 6000 LUX, and the efficiency is about $65 \%$ 72\%. While the illumination is less than 6000 LUX, the bus voltage is instable.

\section{CONCLUSION}

In this paper, a full parallel-connected topology is proposed to the PV, where a single cell is taken as a steady voltage source, which is connected to the bus with a unique converter. Arithmetic is provided to eliminate the efficiency of different PV panels. An ULV converter is introduced to convert the energy. Experiments about the system are given and the results show that the converter has good working characteristics and the converter could collect the cells' power well. PV system, consisted by 100 cells, is used to test the parallel system. The results show that the efficiency of the novel PV system is high and the bus voltage is stable.

\section{REFERENCES}

[1] W.-L. Hsieh, C.-H. Lin, C.-S. Chen et al., "Impact of PV Generation to Voltage Variation and Power Losses of Distribution Systems," 4th International conference on Electric Utility Deregulation and Restructuring and Power Technologies, pp. 1474-1478, July 2011.

[2] I. Kaizuka, T. Ohigashi, H. Matsukawa et al., "PV trends in Japan: New framework for introduction of PV system," in Proc. 34th IEEE Photovoltaic Specialists Conference (PVSC), pp.000712-000716, June 2009.

[3] C. A. Wolden, J. Kurtin, J. B. Baxter et al., "Photovoltaic manufacturing: Present status, future prospects, and research needs," Journal of Vacuum Science \& Technology, vol. 29, issue 3, March, 2011.

[4] J. Bebic, R. Walling, K. O'Brien, B. Kroposki, "The sun also rise," IEEE Power and Energy Magazine, vol. 7, no. 3, pp. 45-54, May-June 2009.

[5] C. P. M. Densulman, T. C .J. van der Weiden, S. W. H. de Haan, F. Ter Heide, and R. J. C. van Zoligen, "Feasibility and development of PV modules with Integrated Inverter: AC modules," in Proc. 12th European Photovoltaic Solor Energy Conf., Amsterdan, The Netherlands, pp.313-315, Apr. 1994.
[6] E. Roman, R. Alonso, and P. Ibanez, "Intelligent PV Module for Grid-Connected PV Systems," IEEE Trans. Indus Electro., vol. 53, no.4, pp.1066-1073, Aug. 2006

[7] L. Gao, R. A. Dougal, S. Liu, and A. P. Iotova, "Parallel-Connected Solar PV System to Address Partial and Rapidly Fluctuating Shadow Conditions," IEEE Transaction on Industrial Electronics, vol. 56, no 5, May 2009.

[8] J. L. Agorreta, M. Borrega, and J. Lopez, "Modeling and Control of N-paralleled Grid-connected Inverters With LCL Filter Coupled Due to Grid Impedance in PV Plants," IEEE Trans. Power Electron, vol. 26, no. 3, pp. 770-775, Mar. 2011.

[9] E. Díaz-Dorado, A. Suárez-García, and C. Carrillo et al., "Influence of the shadows in photovoltaic systems with different configurations of bypass diodes," Internation Symposium on Power Electronics Electrical Drives Automation and Motion, pp.134-139, June. 2010.

[10] J. Wohlgemuth and W. Herrmann, "Hot spot test for crystalline silicon modules," in Proc. IEEE Photovoltaic Spec. Conf., pp. 1062-1063, Jan. 2005.

[11] L. Tang and P. J. Wolfs, "A single Cell Maximum Power Point Tracking Converter without a Current Sensor for High Performance Vehicle Solar Arrays," IEEE PESC, 2005.

[12] L. H. Altas and A. M. Sharaf, "A Novel on-Line MPP Search Algorithm For Pv Arrays," IEEE Trans. Energy Conversion, vol.11, no.4, pp.748-754, Dec. 1996

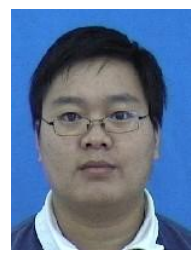

Zhiwen Yu was born in Hunan on September 11, 1987. $\mathrm{He}$ received the Bachelor degree from Shanghai University Of Electric Power, Shanghai, China in 2010 Now he pursues the master degree in the School of Electric Power Engineering, Shanghai Jiaotong University. He mainly focuses his research on FACTS and power system simulation.

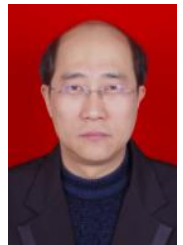

Da Xie was born in Heilongjiang on July 1, 1969. He received the M.S. from Ha'erbin Institute of Technology in 1996 and Ph.D. degrees from Shanghai Jiao Tong University in 1999. He is an associate professor in Shanghai Jiao Tong University, EE department. He mainly focuses his research on FACTS and power system simulation.

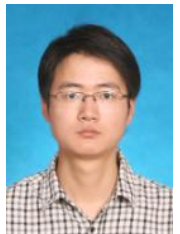

Junqi Feng was born in Henan on March 27, 1988. He received the Bachelor degree from Harbin Institute of Technology, Harbin, China in 2011. Now he pursues the master degree in the School of Electric Power Engineering, Shanghai Jiaotong University. He mainly focuses his research on FACTS and power system simulation. 